\title{
A INVENÇÃO DO ÍNDIO NA MÍDIA: silenciamentos, estereótipos e pluralidades
}

\section{MEDIA AND INDIGENOUS IDENTITY: silences, stereotypes and cultural pluralities}

\author{
Ivânia dos Santos NEVES \\ Universidade da Amazônia (UNAMA) \\ Maurício Neves CORRÊA \\ Universidade da Amazônia (UNAMA) \\ Raimundo de Araújo TOCANTINS \\ Universidade da Amazônia (UNAMA)
}

\begin{abstract}
RESUMO: A mídia representa hoje um dos mais privilegiados espaços de (re)produção das identidades. No Brasil, os 305 povos indígenas e suas 274 línguas nativas, frequentemente, são tomados como uma generalização e ainda hoje, em muitas produções midiáticas, silenciam-se as singularidades destas sociedades. Neste artigo, selecionamos como corpus de análise o filmedocumentário Coluna Norte (1960), cenas da telenovela Uga Uga (2000) e dois perfis de Facebook de mulheres indígenas ativos em 2013. A partir das definições de rede de memória e de intericonicidade, analisamos como estas representações colocam em circulação três diferentes posições sobre o agenciamento das identidades indígenas: o silenciamento, o estereótipo e a pluralidade cultural.
\end{abstract}

PALAVRAS-CHAVE: 1. Intericonicidade. 2. Línguas Indígenas 3. Arqueologia

ABSTRACT: Nowadays, the media is one of the richest spaces to consider the production of identities. Currently, in Brazil, the 305 indigenous people and their 274 native languages often are taken as a generalization and still today in many media productions the silence about the singularity of these people is frequent. In this work, we selected as the corpora the documentary film Coluna Norte (1960), the scenes of soap opera Uga Uga (2000), produced by Rede Globo and the Facebook profiles of two indigenous women in 2013. From memory network settings and inter-iconicity we analyze how these indigenous representations put into circulation three different positions toward indigenous identities: silencing, the stereotype and cultural plurality.

KEYWORDS: Media; Indigenous Identity; Uga Uga; Coluna Norte; Facebook

\section{Introdução}

Desde os primeiros contatos estabelecidos entre os povos que habitavam as américas antes da colonização e as metrópoles europeias, as cartas e as imagens resultantes das expedições marinhas, as principais mídias do início do século XVI, deram início ao agenciamento das formas simbólicas sobre estes povos. A nudez e a antropofagia ganharam muito destaque, pois era necessário inventar um indígena selvagem, desprovido de racionalidade, a fim de que toda a sorte de desrespeito aos direitos humanos fosse justificada (NEVES, 2009).

A xilogravura a seguir é a segunda imagem que circulou na Europa sobre os povos indígenas da América, ele institui uma memória das imagens, que retoma a ideia do homem das cavernas, bem diferente do indígena sul-americano. A forma como estão dispostos os 
restos humanos, braços, perna, cabeça destitui qualquer caráter religioso dos rituais antropofágicos. Não há qualquer referência ao fato de que eles comiam aqueles inimigos que consideravam virtuosos, para que pudessem incorporar estas virtudes. As partes do corpo humano estão dispostas como se tratasse das partes do corpo de qualquer outro animal.

\section{Figura 01: Imagem do Novo Mundo}

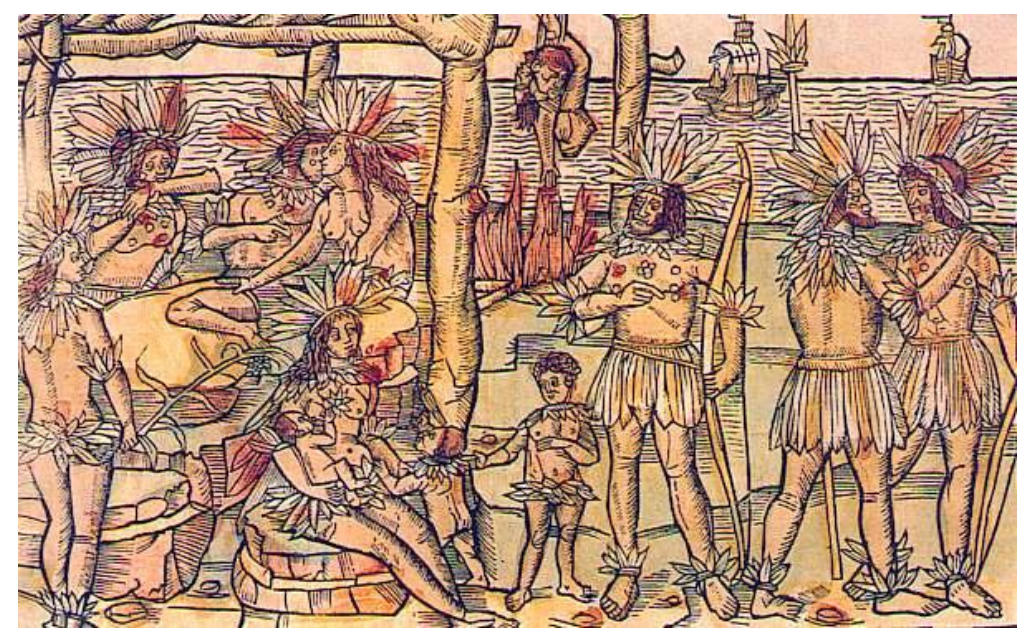

(LEITE: 1995,2)

Esta xilogravura, apesar de ser uma invenção e de suas incoerências, serviu de inspiração para muitas outras imagens que foram produzidas sobre a antropofagia. É quase inacreditável que ainda hoje este tipo de imagem seja uma espécie de guardião da memória "oficial” sobre as culturas indígenas. É exatamente a este aspecto da tradição inventada, já referido no início do capítulo, que Hobsbawm (2008) chama atenção: a repetição como dispositivo de manutenção. Então, em nossa memória visual, tanto a "Imagem do Novo Mundo" como todas as outras produzidas a partir dela estiveram e estão tão repetidas vezes simbolizando o cotidiano das sociedades indígenas, que é muito difícil pensar nos Tupinambá ou em seus contemporâneos sem visualizar estas telas. (NEVES, 2009, 77)

Houve sempre uma batalha discursiva que se inscreveu na produção das identidades indígenas, e ao mesmo tempo em que se introduzia um discurso racista, também desde o início, a resistência a esta hierarquia de racionalidades esteve presente, quer fosse agenciadas pelos próprios europeus, como foi o caso do Bartolomeu de Las Casas ${ }^{1}$, no início do século XVI, quer fosse administradas pelos povos indígenas, se insurgindo com suas formas de vida a despeito das imposições coloniais. Portanto, esta fronteira, a midiática, com todas as suas transformações, sempre mediou os processos de contato, a princípio agenciados pelos europeus, depois pelo Estado brasileiro e hoje, também envolvendo os próprios indígenas, presentes nas redes sociais. Este processo contínuo e difuso foi sempre marcado pela

\footnotetext{
${ }^{1}$ Padre jesuíta que veio à América pela primeira vez com Cristóvão Colombo, notabilizado por sua luta pelos direitos humanos.
} 
resistência e entre outros efeitos, produziu nas sociedades latino-americanas uma condição de "estar ou sentir-se entre":

A diferença colonial cria condições para situações dialógicas, nas quais se encena, do ponto de vista subalterno uma enunciação fraturada como reação ao discurso e à perspectiva hegemônica. Assim, o pensamento liminar é mais do que uma enunciação híbrida. É uma enunciação fraturada em situações dialógicas com a cosmologia territorial e hegemônica. (MIGNOLO, 2003, p.11)

Desde 1999, realizamos projetos de pesquisa e extensão que envolvem discussões teóricas sobre identidades indígenas. Muito cedo, a experiência com estas sociedades indígenas nos fizeram compreender a emergência de discussões acadêmicas que propusessem a desconstrução da generalização imposta pelo sistema colonial, que chama a todos estes povos simplesmente de índio. As discussões a análise da tese "A invenção do índio e narrativas orais Tupi" (NEVES, 2009) faz uma intensa incursão nas formas como a história ocidental e cinco sociedades indígenas, a partir de suas narrativas orais, produziram diferentes identidades e dá início a uma série de trabalhos desenvolvidos na pós-graduação sobre a identidade dos povos indígenas.

Já nas primeiras análises, suas narrativas orais, constituídas por dança, canto, pinturas corporais, apresentavam-se em uma linguagem audiovisual e significavam intensos processos de interação. A postura metodológica de apenas transcrevê-las, em nome de se manter verossímil à realidade dos narradores, muitas vezes, acaba por destituí-las de suas estratégias interacionais, que são bem mais complexas que a palavra falada.

No final de 2009, aconteceu a aprovação do projeto "Crianças Suruí-Aikewára: entre a tradição e as novas tecnologias na escola", cujo principal objetivo era produzir curtasmetragens e livros didáticos com as principais narrativas orais desta sociedade. Em função das atividades desenvolvidas neste projeto, precisamos enfrentar novos desafios em relação à complexidade dos processos que envolvem as narrativas e suas traduções. Nesta trajetória, a definição de cultura proposta por Clifford Geertz foi bastante produtiva:

[o] conceito de cultura que defendo é essencialmente semiótico. Acreditando como Max Weber, que o homem é um animal amarrado a teias de significados que ele mesmo teceu, assumo a cultura como sendo essas teias e a sua análise; portanto não como uma ciência experimental em busca de leis, mas como uma ciência interpretativa, à procura do significado.(GEERTZ, 1978, p.8-9)

Por outro lado, o projeto estabelecia novas formas de interação com os Aikewára em função do uso das "telas" das máquinas fotográficas, das filmadoras e do computador. Nesta dinâmica, definições de etnografia densa e de observação participante, fundamentadas nos pressupostos da antropologia interpretativista, começaram a dar espaço para novas perspectivas metodológicas. Não éramos apenas observadores participantes, pois agenciávamos a identidade indígena daquele povo, traduzindo-a em livros e em audiovisual. Havia um grau a mais de envolvimento e precisamos entender o lugar de fala (FOUCAULT, p. 2000) das pessoas envolvidas no processo e a circulação do poder. 
Também não podíamos nos considerar redentores da cultura Aikewára e muito menos acreditar que nossas tímidas produções seriam uma espécie de redenção das práticas coloniais. Para Beatriz Sarlo (1997, p.121):

Sabemos então que, assim como não existe uma única cultura legítima, em cuja cartilha todos devem aprender a mesma lição, tampouco existe uma cultura popular tão sábia e poderosa que possa ganhar todos os confrontos com a cultura de massa, fazendo com os produtos da mídia uma colagem livre e orgulhosa, nela inscrevendo seus próprios sentidos e apagando os sentidos e idéias dominantes na comunicação de massa. Ninguém pode fazer uma operação tão a contrapelo nas horas vagas, enquanto assiste à televisão.

Os Aikewára se reconheciam com identidades cambiantes, mas diante das telas, quiseram marcar uma identidade indígena, que se definia a partir da expectativa do outro. Eles sabiam que, para serem reconhecidos como indígenas, precisavam falar sua língua tradicional e aparecer com os corpos vestidos com tintas de jenipapo e urucum. Estes enunciados identitários, hoje, presentes na programação televisiva, nas redes sociais, também estavam nas primeiras representações que circularam sobre estas sociedades fora da América, e, embora sejam imperativos em algumas circunstâncias, a ordem que estabelecem não são suficientes para aprisionar estas pessoas em uma única identidade.

Sabemos, hoje, que as identidades culturais não são rígidas, nem muito menos, imutáveis. São resultados sempre transitórios e fugazes de processos de identificação. Mesmo as identidades aparentemente mais sólidas, como a de mulher, homem, país africano, país latino-americano ou país europeu, escondem negociações de sentido, polissemia, choques de temporalidades em constante processo de transformação, responsáveis em última instância pela sucessão de configurações hermenêuticas que de época para época dão corpo e vida a tais identidades. Identidades são, pois, identificações em curso. (SOUSA SANTOS, 2010, p.135).

A inquietação identitária dos Aikewára, que se movimentava entre suas negociadas práticas culturais e o agenciamento midiático da identidade indígena - motivou e continua motivando, entre nós, novas pesquisas, que se propõem a entender a complexidade deste processo de produção de sentido sobre as identidades indígenas. E, por mais que já tenhamos avançado um pouco nas pesquisas voltadas para esta questão, estamos apenas no começo.

No início de 2010, no Programa de Comunicação, Linguagens e Cultura da Universidade da Amazônia (UNAMA), junto com os alunos que participaram do primeiro projeto, fundamos o GEDAI-Grupo de Estudo Mediação e Discurso com Sociedades Amazônicas. O grupo trabalha voltado para os processos de mediação com diferentes populações amazônicas e não apenas com povos indígenas. Procuramos entender a região não como um espaço geográfico delimitado pelo Estado brasileiro, mas a partir das particularidades culturais, históricas e identitárias destas sociedades.

O GEDAI produziu 05 dissertações no Programa da UNAMA sobre a (re)produção das identidades indígena na mídia. Agora em 2013, nossas atividades estão concentradas na Universidade Federal do Pará, no Programa de Comunicação, Amazônia e Cultura, na linha de pesquisa Mídia, Cultura e Amazônia e desenvolvemos o projeto aprovado na Chamada Universal $\mathrm{CNPq}$ "A invenção do índio na mídia: discursos e identidades" e estamos trabalhando em mais duas dissertações voltadas para estas discussões. As análises que 
apresentamos aqui são resultados de três diferentes pesquisas realizadas pelo GEDAI, desdobramentos de nossas discussões sobre as identidades indígenas.

Neste artigo, tomando como referência o método arqueológico, proposto por Michel Foucault, que nos possibilita entender o funcionamento do discurso sobre os povos indígenas em um período de longa duração, a definição de intericonicidade, formulada por J.J. Courtine, interessada na memória das imagens, assim como as análises semiológicas propostas por Rosário Gregolin, preocupadas em compreender a produção das identidades nas mídias, analisamos este processo discursivo de invenção do índio em duas produções audiovisuais: o filme-documentário Coluna Norte (1960), que circulou nos cinemas brasileiros nos anos de 1960, um capítulo da telenovela Uga-Uga (2000), veiculada pela Rede Globo e em dois perfis de mulheres indígenas no Facebook ativos no ano de 2013. O objetivo é mostrar o agenciamento destes discursos em diferentes espaços de produção de sentido na mídia e de como estes processos reafirmam e refutam a circulação cotidiana dos sentidos sobre os estereótipos indígenas, na contemporaneidade e ao mesmo tempo, estabelecem uma rede de memória que atravessa estas diferentes materialidades, inscritas em diferentes condições de possibilidades históricas.

\section{Discurso, mídia e identidade}

Os procedimentos metodológicos de nossas análises pautam-se na perspectiva teórica proposta por Michel Foucault, em Arqueologia do Saber (1969/2005), que estabelece um movimento de regularidades e dispersões na constituição histórica dos discursos. Nesta perspectiva, olhamos para a história do presente não como uma regularidade, que levaria a supor que as identidades indígenas estão presentes na mídia da mesma forma e pelas mesmas razões.

Partimos do pressuposto que a mídia se organiza a partir de relações de poderes, historicamente construídas e que, no jogo dos acontecimentos, vão construindo novas estratégias de dominação, mas que sempre deixam margem para movimentos de resistências. A partir das regularidades e das dispersões com que a história das sociedades indígenas se escreve, é possível "estabelecer redes de memórias que evidenciam as articulações entre práticas discursivas e a produção de identidades na mídia" (GREGOLIN, 2007, p.03).

As descrições feitas por Cristovão Colombo e sua geração, no final do século XV, a partir de uma série de dispersões, lançaram as bases da memória discursiva do Ocidente sobre os "índios" e esta história vai percorrer caminhos diversos, com discursos que serão retomados, refutados, afirmados, negados. Compreender como as produções midiáticas constroem, hoje, as diferentes identidades indígenas é fazer a história descontínua dos acontecimentos que envolvem estes povos e sua relação com as sociedades ocidentais.

Sabemos que a mídia exerce um papel fundamental na (re)produção das identidades, no mundo ocidental, pois "fornece o material com que muitas pessoas constroem o seu senso de classe, de etnia e raça, de nacionalidade, de sexualidade, de "nós" e "eles" (KELLNER, 2001, p.9). Esta perspectiva dos efeitos de sentidos produzidos pelos meios de comunicação permite pensar os enunciados colocados em circulação pela mídia como algumas das materialidades discursivas mais significativas da história do presente. A tecnologização dos meios de comunicação das sociedades pós-industriais produziu dispositivos discursivos que passaram a interferir decisivamente em suas práticas culturais. Hoje, pensar em uma análise das produções de sentido pela mídia não se limita mais a compreendê-la como uma "ação representacional". 
A mídia, na atualidade, alcançou uma pluralidade de novos espaços, com a web $2.0 \mathrm{e}$ seus blogs e sites de relacionamentos, anunciando a "democratização" da comunicação. Apesar de tantas transformações, no entanto, não se pode ignorar que todos estes processos de mediação continuam entoados pelas antigas e remasterizadas relações de poder, atualizadas em novos formatos, que dividiram o mundo entre metrópoles e colônias. $\mathrm{O}$ espaço que os povos indígenas ocupam nos meios massivos traduz bastante esta história que se escreve desde o início da colonização.

Quando um acontecimento relacionado aos povos indígenas ganha destaque internacional e exige uma posição do Estado brasileiro, ele tem mais chance de entrar na pauta dos meios massivos. Em contraponto a esta situação, durante meses é possível um absoluto silenciamento a respeito destas sociedades. Nas redes sociais, a dinâmica é diferente e já houve postagens no Facebook com visibilidade internacional que obrigaram o governo brasileiro a rever uma liminar de despejo contra os Kaiowá-Guarani, no Mato Grosso do Sul.

Observamos, nas pesquisas já realizadas, que as produções midiáticas seguem uma dinâmica que, em linhas gerais, orienta-se a partir de três movimentos: a produção de silenciamentos, a reafirmação dos estereótipos e a perspectiva da pluralidade cultural. $\mathrm{O}$ recorte do corpus de análise, que apresentamos em três atos, a seguir, considerou estas posições.

\section{O silenciamento: primeiro ato}

O filme Colona Norte (1960) é classificado como um cine-documentário. Estas produções, muitas vezes patrocinadas por empresas estrangeiras, neste caso pela MercedesBens, funcionavam como campanhas institucionais de projetos do governo brasileiro. Dirigido por Jean Manzon, este filme foi produzido durante o governo de Juscelino Kubitschek, mas esta prática de fazer propaganda nos cinemas vai se consolidar ainda mais no período da ditadura militar. O vídeo mostra a construção da rodovia Belém-Brasília e exalta a conquista do "pesadelo verde", forma como ele se refere à floresta Amazônica. Neste período, havia uma preocupação muito grande por parte do governo brasileiro e de empresas interessadas em explorar a Amazônia, em integrar a região ao país.

O discurso de integração, ainda hoje em evidência com a construção da Usina Hidrelétrica de Belo Monte, é bastante recorrente em relação à Amazônia e sempre se tencionou entre os interesses estrangeiros e as práticas culturais de moradores da região, desde que o Brasil se tornou um país independente de Portugal em 1822. A Amazônia brasileira não era Brasil, era outra colônia portuguesa, a Província do Grão-Pará e Maranhão e não foi fácil, nem simples, ao Império Brasileiro incorporar esta província ao território nacional. Apenas em 1835, depois de violentamente sufocada a tentativa de independência da revolta popular que ficou conhecida como Cabanagem, a Amazônia foi incorporada ao território brasileiro, mas a dificuldade de integrar a região não acabou neste momento.

Para entender como este processo de integração aparece atualizado no filme Coluna Norte, vamos analisar algumas imagens. 


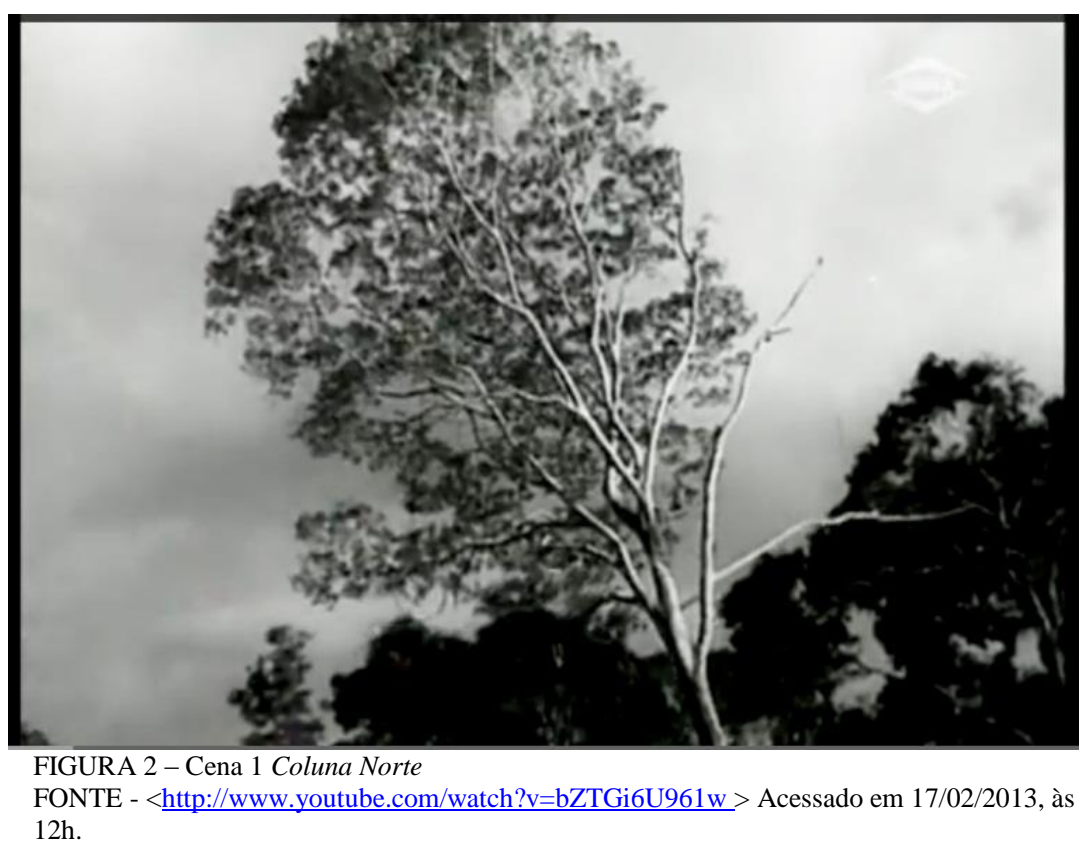

Neste primeiro framer, a árvore caindo representa uma cena emblemática do que significava o discurso desenvolvimentista desta época. Havia incentivos fiscais para os "empreendedores" que conseguissem devastar $100 \%$ de suas propriedades. A floresta em pé significava atraso, retrocesso. Estas imagens deveriam ser expostas nas salas de cinema brasileiras para promover uma imagem positiva do governo. Instituía-se uma ordem no olhar: as árvores caindo produziam o progresso da região e do Brasil.

As sociedades indígenas que vivam nestes territórios são absolutamente silenciadas. $\mathrm{Na}$ fala eloquente do narrador, ele faz a seguinte convocação:

\begin{abstract}
A primeira árvore tombada... Um areal de rios, um mundo de sagas e mistérios. Um pesadelo cheio de duendes e ameaças separava o norte e o coração do Brasil. A estrada Belém-Brasília começava. Vinde meus filhos de desteimar! Segue em ordem. Nossas armas preparadas, vossos machados de gume cortante. Pioneiros, oh pioneiros! (Coluna do Norte, 1960. grifo nosso)
\end{abstract}

Não havia pessoas no caminho da rodovia, apenas "duendes", que ameaçavam o progresso. Embora algumas sociedades indígenas tenham sido exterminadas em função da construção, eles não aparecem no filme. As imagens e falas produzem uma verdade: as rodovias só fariam bem à região. Num processo de intericonicidade, as cenas retomavam outras narrativas audiovisuais, que afetavam bastantes os brasileiros que frequentavam os cinemas, naquele momento, e acionam suas memórias, permeadas por filmes hollywoodianos de faroeste e por filmes documentários ufanistas brasileiros. Sobre a intereconicidade explica Courtine (2011, p.17):

O campo da fala Pública está atravessado, saturado por imagens nas quais percebemos, ao mesmo tempo, a força de seu impacto e a instantaneidade de sua obsolescência. É crucial compreender como elas significam, como uma memória de imagens as atravessa e as organiza, ou seja, uma interconicidade que lhes atribui sentidos reconhecidos e partilhados pelos sujeitos políticos que vivem na sociedade, no interior da cultura visual. 
Para Milanez (2011, p.39):

Olhar para a imagem sob o efeito da intericonicidade é de uma arqueologia do imaginário humano, construída não sobre a cristalização homogeneizante de uma imagem única, mas sobre o movimento dos deslocamentos, sucessão, interposições, apagamentos, reestruturações de imagens que existem sob a batuta da regência dos movimentos nem sempre harmônicos da história.

$\mathrm{Na}$ figura seguinte, a presença dos caminhões e tratores representa a modernidade chegando à região. A tecnologia enfrentando o "inferno verde". Novamente, uma memória das imagens é retomada. Estes tratores e o ônibus representavam a sofisticação tecnológica desta época.

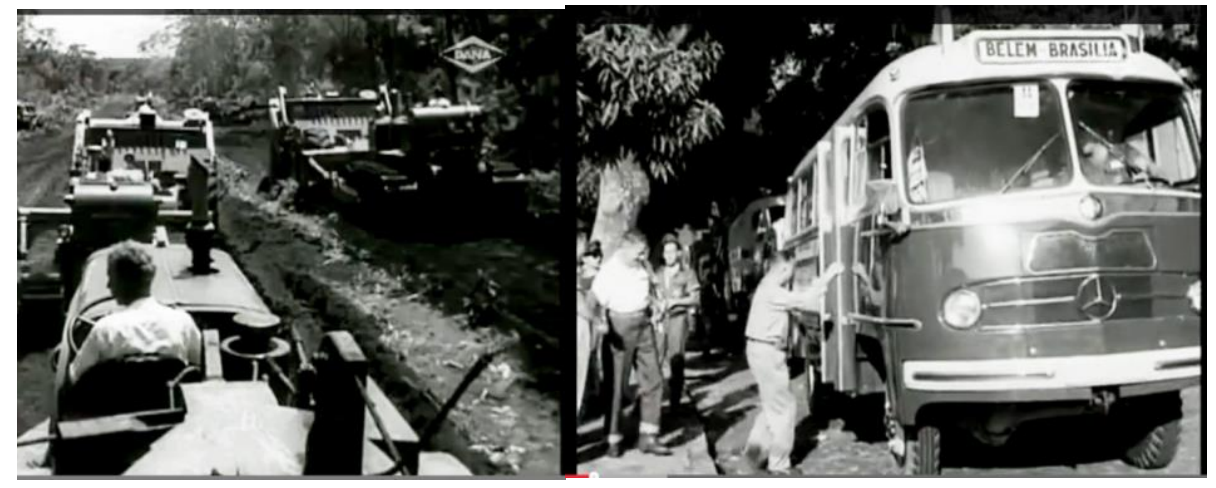

FIGURA 3 - Tratores e ônibus na Belém-Brasília

FONTE - <http://www.youtube.com/watch?v=bZTGi6U961w> Acessado em 17/02/2014, às 10h

O filme usa de várias práticas discursivas para justificar a construção da rodovia. Há uma seleção de imagens, sons e palavras que buscam emocionar o espectador. A trilha, a narração ufanista e bem pontuada, criam um clima épico. Os enquadramentos das cenas foram pensados para exaltar a conquista dos sujeitos que no filme, o narrador chama de "pioneiros". Os discursos da modernização e da integração da Amazônia estão fortemente exacerbados na produção. (CORRÊA, 2013, 34)

Segundo Renato Ortiz (1988, p.14), na década de 1970, as salas de cinema espalhadas pelo país contavam com mais de 200 milhões de espectadores por ano e os cinedocumentários eram exibidos antes dos filmes principais. Hoje, estes cine-documentários estão disponíveis no site YouTube e não produzem mais os mesmos efeitos de sentido. De qualquer forma, é bastante significativo ainda podermos acessá-los, pois suas cenas permitem estabelecer uma rede de memórias audiovisuais sobre as sociedades amazônicas e os acontecimentos que as envolveram naquele período. É possível percebemos, hoje, como foi agenciado a silenciamento sobre os povos Aikewára, Gavião, Apinaé, entre outros, que tiveram suas histórias cortadas pelas rodovias que cruzaram a Amazônia. 


\section{Segundo Ato: as comemorações dos 500 anos}

No ano 2000, no rastro das comemorações dos 500 anos do Brasil, a Rede Globo colocou em circulação várias produções com personagens indígenas nas tramas principais. A telenovela Uga Uga e as minisséries A invenção do Brasil e A Muralha trouxeram para as telas diferentes posições discursivas sobre as identidades indígenas.

A teledramaturgia brasileira, entendida como produções híbridas que estabelecem um intercâmbio entre vários campos, como o cinema, o teatro, o rádio, e demais categorias televisivas (MALCHER, 2009), tem na telenovela o seu principal expoente. Ao contrário das primeiras décadas de sua implantação, quando contavam com poucos recursos técnicos, hoje, elas são o produto de maior popularidade e rentabilidade da televisão brasileira.

Mais do que um gênero televisivo, a telenovela é uma das expressões mais significativas da cultura brasileira. Para Lopes (2009), as telenovelas são um dos mais importantes espaços de problematização do Brasil e conseguem, como nenhum outro produto televisivo, discutir tanto as intimidades privadas como os problemas públicos. Por isso mesmo, elas também representam um, potente espaço de manipulação da opinião pública no país.

Para Martín-Barbero (2001), as telenovelas brasileiras têm como base o melodrama, no entanto, diferente do que acontece em outros países latino-americanos, elas vão além desse gênero dramático e inserem em suas tramas assuntos que fazem parte do cotidiano do público. Assim, aproximam a ficção da realidade dos telespectadores. Nesta perspectiva, podemos compreender que a presença de personagens indígenas na teledramaturgia brasileira, no ano 2000, estava bem de acordo com as discussões sobre a colonização, naquele período.

Aqui, nesta análise, vamos destacar o personagem protagonista da telenovela $U g a$ $U g a$, Tatuapu, que se caracteriza pelo estereótipo do bom selvagem. Interpretado pelo ator loiro e de olhos claros, Cláudio Heinrich, na trama, sua identidade indígena foi acidental. No início da narrativa, este personagem aparece como filho de uma família rica, que ficou perdido na floresta. A construção deste personagem guarda profundas semelhanças com a história de Tarzan, da literatura e do cinema estadunidense.

Quando criança, Tatuapu participou de uma expedição pela floresta amazônica com os pais, mas um acontecimento inesperado mudou a vida do menino: todos foram mortos e apenas ele sobreviveu. Mas, ao invés de ser protegido pelos animais da floresta, a criança foi adotada por um povo indígena e se transformou em Tatuapu.

Somente adulto, ele conhece a sua família de sangue e voltou ao Rio de Janeiro para viver ao lado dela. De maneira cômica, característica das telenovelas do horário das 19 horas veiculadas pela Rede Globo (LOPES, 2003), o desenrolar de Uga Uga mostra o rapaz tentando se adaptar à grande cidade. As imagens que vamos analisar a seguir são do capítulo em que Tatuapu chega à casa de seu avô Nikos, interpretado pelo ator Lima Duarte. Ele aparece com o corpo pouco vestido com roupas e adereços indígenas, para marcar sua identidade. 


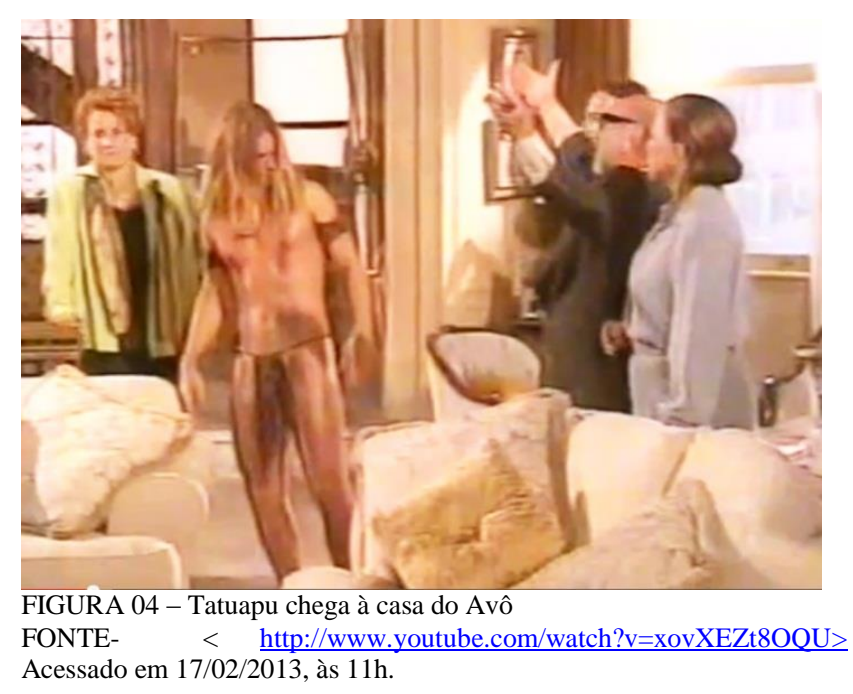

Nesta cena, na sala da casa de seu avô, de quem é o único e até então desaparecido herdeiro, há uma grande confusão, porque Tatuapu não entende a língua portuguesa. $\mathrm{O}$ avô tenta insistentemente lhe explicar o que aconteceu, mas o rapaz fala na língua de sua aldeia e começa a se exaltar. Com muito humor, outros personagens que estão na cena comentam que esta barreira linguística será uma facilidade para tirarem sua fortuna. A dificuldade com a língua é uma recorrência entre os personagens indígenas e ao mesmo tempo em que representa a ingenuidade, também reforça um discurso de limitação cognitiva.

No framer a seguir, ainda no mesmo capítulo, Tatuapu agarra os seios da namorada de seu primo, a personagem Tatiana, interpretada pela atriz Daniela Winits. Motivado pela fala de Nikos: "Só vão morar nesta mansão as pessoas que você quiser!", o primo estimula o rapaz a atacar sua noiva.

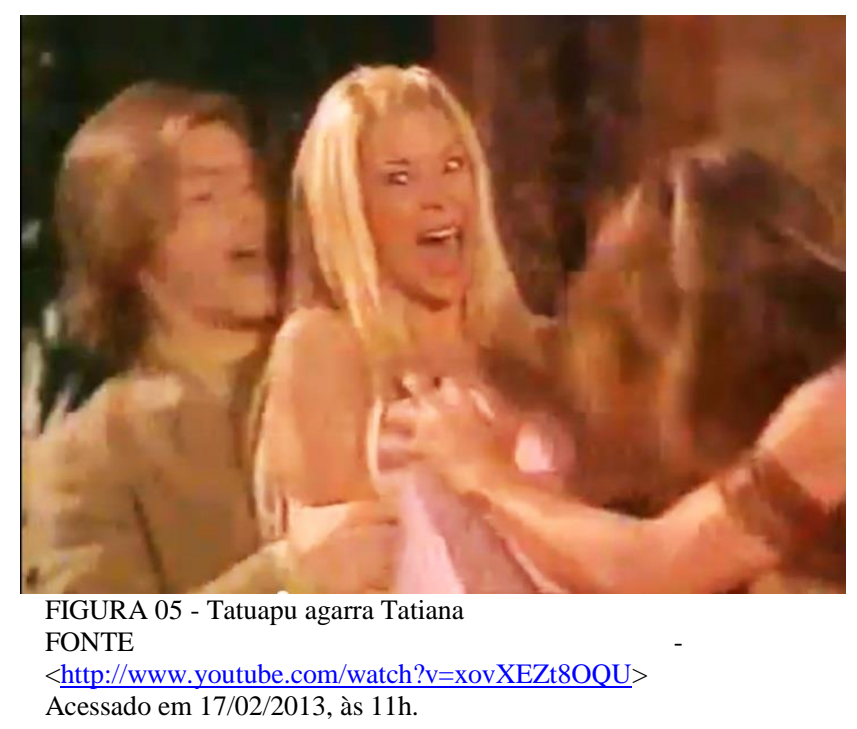

Esta atitude ratifica a selvageria do indígena e encarna o próprio estereótipo do bom selvagem: alguém ingênuo, com limitações, que precisa ser tutelado no convívio social. $\mathrm{Na}$ construção deste personagem, os enunciados verbais e visuais retomam uma rede de memória 
que nos faz pensar na pureza do índio Peri, do romance Guarani, de José de Alencar, ou da inocência descrita na Carta de Caminha a respeito da população nativa do Brasil.

As análises dos produtos televisivos precisam compreender os processos de interação que estabelecem com a sociedade brasileira. De acordo com Braga (2006), o sistema de interação social sobre a mídia ocorre após a recepção, quando a sociedade age sobre o conteúdo de um determinado produto midiático, debatendo sobre os assuntos que foram exibidos, contestando, interpretando, enfim, interagindo com o produto que foi produzido e transmitido ao público.

No ano de exibição de $U g a U g a$ e das outras produções globais, o comércio brasileiro vendeu uma grande quantidade de adereços indígenas. Nas feiras, nas lojas de departamento, nas boutiques, era muito comum encontrar objetos de inspiração indígena. Os adereços do estereotipado Tatuapu e os sentidos que esta telenovela produziu se espalharam por todas as regiões do Brasil.

\section{Terceiro ato: mulheres indígenas no Facebook}

Para finalizar as análises, passaremos aos perfis de duas mulheres indígenas no Facebook, ativos no ano de 2013. Como elas são de duas sociedades diferentes: Ticuna e Guajara, não podemos conformá-las na definição genérica de índio. Atualmente, no Brasil, vivem 305 povos indígenas, que falam 274 línguas nativas. As sociedades indígenas contemporâneas são bastante heterogêneas, se por um lado existem populações indígenas compostas por menos de 30 pessoas, por outro, há povos como os Mbyá-Guarani com mais de 10 mil indígenas. Suas práticas culturais também são bem diferentes. Então, não podemos pensar que os usuários que assumem identidades indígenas estão na internet pelas mesmas razões e com os mesmos objetivos.

Sabemos que a rede mundial de computadores é um espaço onde os sujeitos têm maior liberdade para procurar por informações de seus interesses particulares e podem fazer uma leitura não-linear dos conteúdos: que não depende do perfil de cada veículo, da grade de programação ou dos horários específicos. Cada pessoa tem a possibilidade de acessar a informação por diferentes caminhos e linguagens, responder aos conteúdos e interagir com outros usuários, produzir materiais específicos, disponibilizá-los em rede etc. (LÉVY, 1999).

Para analisar os dois perfis, vamos considerar que as duas indígenas compreendem o que significa a dinâmica do Facebook, que se distancia da interação proporcionada por meios como a TV ou o rádio, por exemplo, onde o fluxo de informação se estabelece de maneira desigual. Pela frequência das duas neste site de relacionamentos, elas não desconhecem que estas mídias sociais representam: "aquela zona permanente de autoexposição e visibilidade" (KEEN, 2012, p.05).

Primeiro, alguns enunciados colocados em circulação pela Índia Ticuna Weena Miguel. Artista plástica, com 24 anos, ela coloca a palavra "Índia" no seu login e se intitula uma "pessoa pública". Em seu perfil, há quase três mil seguidores, que fazem comentários positivos sobre suas postagens diárias e seus talentos artísticos. Até maio de 2013, a Índia Ticuna postou quase oitocentas fotografias e este número revela que a usuária põe em funcionamento a definição de Andrew Keen (2012) em relação às mídias sociais, compreendidas por ele, como palco principal da existência humana. Em todos os perfis de Facebook, pela própria estrutura deste site de relacionamento, que permite a postagem de imagens fixas e imagens em movimento, a cultura visual é bastante valorizada.

Nesta primeira imagem, a seguir, ela aparece bem dentro da expectativa que se tem sobre uma mulher indígena. Pintada e com pouca roupa, sua imagem faz um apelo à 
sensualidade. Este enunciado nos remete à memória da personagem Iracema, de José de Alencar, cujas imagens são frequentes nos livros didáticos, ou mesmo na programação televisiva. Neles não há surpresa, pois afirmam o estereótipo da mulher indígena com o qual nós temos muita facilidade de lidar. Por meio da imagem percebemos que não há intenção em refutar os discursos estabilizados sobre as mulheres indígenas, ao contrário, existe um reforço destes discursos.

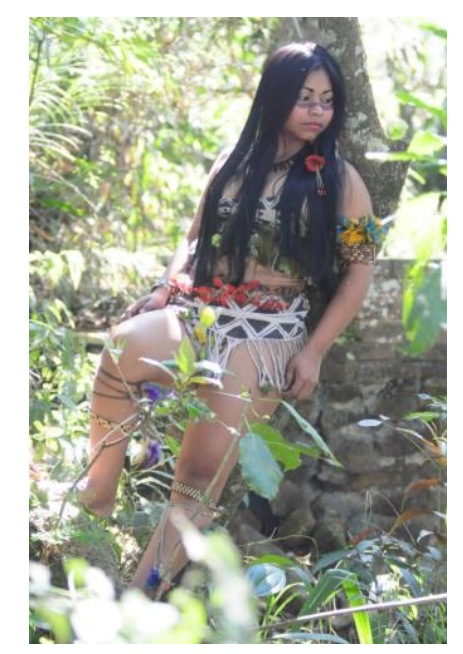

FIGURA 06: India Ticuna

FONTE- <www.facebook.com/indiatikuna.miguel?fref=ts>

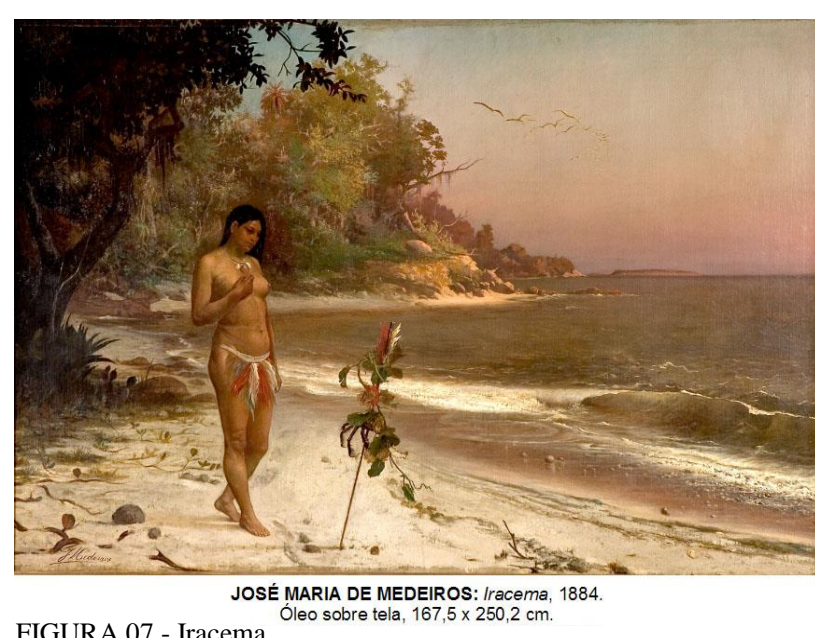

FIGURA

FONTE- < www.estudosliterariosnaweb.blogspot.com.br/2010/06/iracema-osimbolo-do-brasil-e.html> Acessado em 10/02/2013

Na segunda imagem da indígena, a seguir, que faz parte de uma série com mais de 30 fotografias, ela coloca em circulação enunciados que lhe conferem uma outra identidade e não mais a indígena. Atualmente, ela mora num castelo com seu marido, um maestro famoso, no estado de São Paulo. Na foto, eles estão na sacada da sala. Quando olhamos esta imagem, de imediato, ela se filia a uma rede de memória imagética que nos faz lembrar cenas dos contos de fadas, como a que aparece ao lado. Agora, ela é uma princesa ocidental e não mais uma indígena da floresta. Para quem ainda acredita em identidades fixas, diante desta imagem, não há qualquer possibilidade de considerá-la uma mulher indígena. Em seu perfil, Índia Ticuna se apropria deste espaço de visibilidade para refutar e reafirmar os estereótipos.

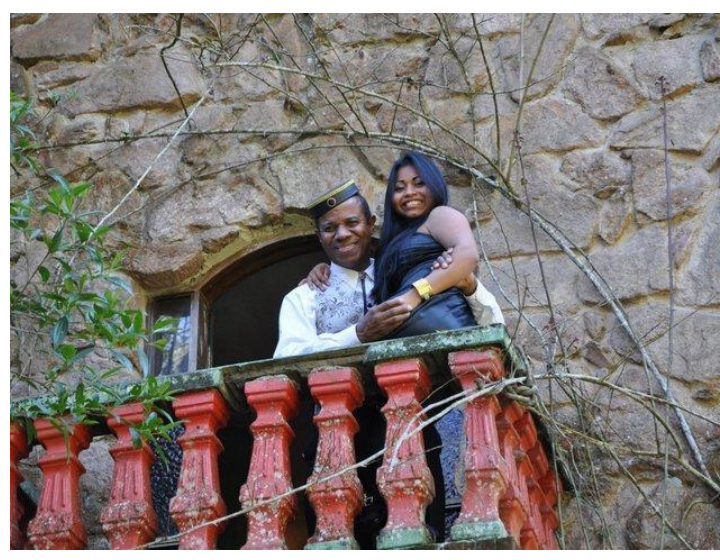

FIGURA 8- Índia Ticuna e seu marido FONTE - < www.facebook.com/indiatikuna.miguel?fref=ts>

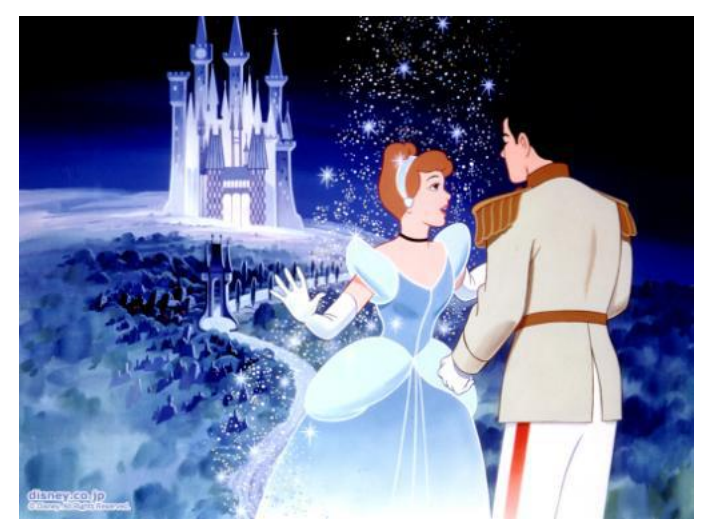

FIGURA 09: A cinderela e o Príncipe

FONTE: <www.barbaraoliveirachaves.blogspot.com.br/2012/07/ sapatinho-de-cristal.html> Acessado em 10/02/2013 
Nos enunciados do perfil de Sônia Guajajara, a identidade de uma mulher indígena se produz em outra direção. A imagem a seguir revela outra forma de desconstruir o estereótipo em relação às mulheres indígenas

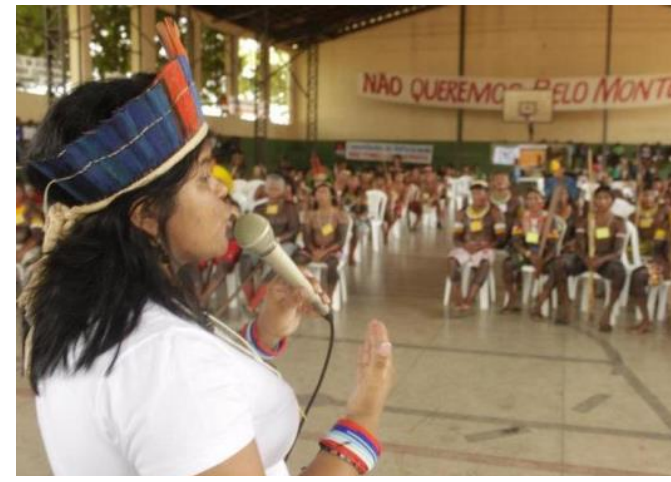

FIGURA 10- Sônia Guajajara

FONTE - <www.facebook.com/soniaguajajara?fref=ts >

Sonia, hoje, é uma das principais lideranças indígenas no Brasil e a maneira como constrói sua identidade apresenta outra forma de subversão: uma liderança política, indígena e mulher. Na próxima foto, aparecem a presidente Dilma Roussef e Sônia Guajajara. Quase contraditoriamente, as duas estão rindo, mas observe que a presidente é bem mais alta e o cabelo dela contrasta com o cocar da Sonia. A indígena entrega uma carta em protesto contra a PEC 37 que, se aprovada, alteraria as leis de demarcação de terras indígenas no Brasil.

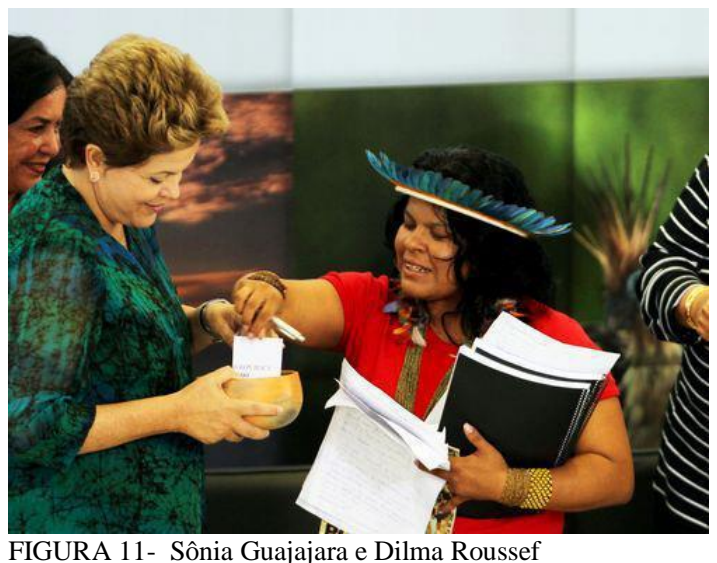

FONTE - <www.facebook.com/soniaguajajara?fref=ts>

O discurso do corpo da indígena se inscreve em relação ao corpo da presidente, a partir de estranhamentos e aproximações. Dilma Roussef representa o poder do Estado brasileiro, que tem autorizado historicamente o desrespeito às nações indígenas brasileiras. O poder do Estado tem legitimado projetos e invasões que expropriam os indígenas de suas próprias terras, disponibilizando essas áreas e suas riquezas naturais para as grandes empresas. $\mathrm{Na}$ esteira deste percurso histórico turbulento, o encontro destes dois discursos, representados pelos corpos da presidente Dilma Roussef e da liderança indígena Sonia Guajajara, coloca em evidência as tensões políticas empreendidas ao longo da história brasileira entre o poder do Estado e os povos indígenas. (TOCANTINS, 2013, p.74) 
Entre os enunciados que estas duas mulheres indígenas colocam em circulação no Facebook sobre sociedades indígenas e sobre mulher há uma grande diferença. Índia Tícuna e Sônia Guajajara, em seus perfis, mostram que as mulheres indígenas não estão neste site de relacionamentos pelas mesmas razões. E assim, chegamos ao terceiro ato: a pluralidade cultural.

A internet, de fato, representa um espaço privilegiado para interações, mas ela não substituiu os meios de comunicação de massa. Ao contrário, ao operar por uma lógica diferente das dinâmicas desenvolvidas pelas mídias massivas, ela se estabelece como um ambiente complementar às dinâmicas em sociedade (WOLTON, 2007).

Estas possibilidades alimentam o sonho de que temos total liberdade na rede e que neste ambiente, estaríamos livres de qualquer controle. Ela também representaria a concretização da utopia de igualdade de participação e os indivíduos participariam da mesma forma que as grandes corporações midiáticas. Essa perspectiva generaliza a compreensão da maneira como as interações acontecem em rede. Para Jesús Martín-Barbero (2004), não podemos esquecer que toda tecnologia é, antes de tudo, uma manifestação cultural. Mesmo diante da possibilidade de construir conteúdos pessoais e de disponibilizá-los no ambiente virtual, não significa que a participação entre os diferentes sujeitos ocorra da mesma maneira.

\begin{abstract}
A expressão cultura participativa contrasta com noções mais antigas sobre a passividade dos espectadores dos meios de comunicação. Em vez de falar sobre produtores e consumidores de mídia como ocupantes de papéis separados, podemos agora considerá-los como participantes interagindo de acordo com um novo conjunto de regras, que nenhum de nós entende por completo. Nem todos os participantes são criados iguais. Corporações - e mesmo indivíduos dentro das corporações da mídia ainda exercem maior poder do que qualquer consumidor individual, ou mesmo um conjunto de consumidores. E alguns consumidores têm mais habilidades para participar dessa cultura emergente do que outros (JENKINS, 2009, p.30).
\end{abstract}

Sempre houve formas de resistências diante das produções midiáticas massivas e sempre foi possível aos sujeitos se valeram de táticas para manipular ou alterar a prudução dos sentidos e ressignificar as identidades de acordo com sua realidade (CERTEAU, 1998). Os Aikewára, diante das telas que traduziam suas narrativas sabiam bem disso. Essas táticas da recepção são exatamente as formas de trapacear o hegemônico e subverter a ordem e mesmo diante dos meios massivos, não houve apenas a produção dos estereótipos e silenciamento em relação às sociedades indígenas.

\title{
6. Considerações Finais
}

Podemos definir a invenção do índio como práticas discursivas que inventaram a tradição indígena que habita o imaginário brasileiro. Nesta perspectiva analítica, a linguagem é tratada em sua dimensão histórica, compreendida a partir das condições de produção em que foi criada, como uma prática social que se materializa em discursos.

Eric Hobsbawm (2008, p.9) fala sobre dois tipos de tradição inventada: uma seria fortemente institucionalizada, enquanto a outra se constituiria gradativamente, sem que fiquem claros os interesses aos quais ela se colocava a serviço. Ele também assinala que estas tradições nem sempre conseguem se estabelecer por um longo período de tempo. Em relação à invenção do índio, que nasce dos interesses coloniais, mas se mantém no Estado brasileiro, 
trata-se de uma invenção fortemente institucionalizada e bastante duradoura, ainda hoje alimentada pela mídia, pela educação e pela falta de políticas públicas efetivas.

Por tradição inventada entende-se um conjunto de práticas, normalmente reguladas por regras tácitas ou abertamente aceitas; tais práticas, de natureza ritual ou simbólica, visam inculcar certos valores e normas de comportamento através da repetição, que implica, automaticamente uma continuidade em relação ao passado. (HOBSBAWM \&RANGER, 2008, p.9)

A invenção do índio, no entanto, implica pelo menos dois sentidos da palavra invenção. A partir de Nietzsche (1978, p.92), podemos entender que se trata de uma falsificação forjada pelas relações de poder do sistema colonial, que instituiu um índio genérico. Este primeiro sentido está bastante associado aos processos de silenciamento ou a reprodução dos estereótipos que aparecem no Coluna Norte e na telenovela Uga Uga.

Por outro lado, também é possível entendermos que a aparente condição de passividade das sociedades indígenas foi determinada pela superioridade bélica dos europeus. Muitos indígenas, quando foi possível, resistiram e ainda hoje, apesar das inúmeras dificuldades que enfrentam, continuam reinventando suas tradições e demarcando suas novas fronteiras culturais nas redes sociais, como Sônia Guajajara e Índia Ticuna. Neste sentido mais construtivo, a invenção é um exercício de resistência e de criatividade das sociedades indígenas (FAULHABER, 1997, p.88).

Agora, as identidades indígenas se forjam na internet a partir de enunciados verbais e visuais mediados pelas próprias indígenas. Contudo, o fato de assumirem este processo nas redes sociais não significa que haverá uma profunda alteração na ordem do olhar em relação as suas culturas. Isto pode acontecer ou não, pois não podemos desconsiderar que eles também são sujeitos históricos e hoje, também estão atravessados pelos discursos que circulam na mídia, nas escolas, nas conversas cotidianas, nas igrejas.

\section{REFERÊNCIAS}

BRAGA, José Luiz. Constituição do campo da comunicação. In Verso e reverso, XXV(58): 62-77, janeiro-abril. Porto Alegre: Unisinos, 2011.

CERTEAU, Michel de. A invenção do cotidiano: artes de fazer (vol.1). $3^{\text {a }}$ edição. Petrópolis, RJ: Editora Vozes, 1998.

CORREAA, Maurício Neves. Os Akewara e a mídia: relações de poder, cultura e mediação. Dissertação de Mestrado. Belém: Universidade da Amazônia, 2013.

COURTINE, J-J. Discurso e imagens: para uma arqueologia do imaginário. In: PIOVEZANI, C; CURCINO, L; SARGENTINI, V. Discurso, semiologia e história. São Carlos: Claraluz, 2011.

FAULHABER, Priscila. A reinvenção da Identidade Indígena no Médio Solimões e no Japurá In. Anuário Antropológico/96. Rio de Janeiro: Tempo Brasileiro, 1997

FAUSTO NETO, Antônio. Fragmentos de uma "analítica" da midiatização. Revista Matrizes, vol 1, no. 2, 2008. 
FOUCAULT, Michel. Microfísica do poder. 26a edição. Rio de Janeiro: Edições Graal, 2008. A arqueologia do Saber. Rio de Janeiro: Forense Universitária, 2005.

A ordem do discurso: aula inaugural no Collège de France, pronunciada em 2 de dezembro de 1970. $3^{\text {a }}$ edição. São Paulo: Edições Loyola, 1996.

GEERTZ, Clifford. A interpretação das culturas. 1ª edição. Rio de Janeiro: LTC, 2008.

GREGOLIN, Maria do Rosário. Análise do Discurso e mídia: a reprodução das identidades. Revista Comunicação, Mídia e Consumo, São Paulo, Vol. 4, No11, 2007

HOBSBAWM, E. ; RANGER, T. A invenção das tradições. São Paulo: Paz e Terra, 2008.

JENKINS, Henry. Cultura da convergência. $2^{a}$ edição. $2^{a}$ Reimpressão. São Paulo: Aleph, 2012.

KEEN, Andrew. Vertigem digital: por que as redes sociais estão nos dividindo, diminuindo e desorientando. Rio de Janeiro: Zahar, 2012.

KELLNER, Douglas. A cultura da mídia. Bauru: Editora EDUSC, 2001.

LÉVY, Pierre. Cibercultura. São Paulo: Editora 34, 1999.

LOPES, Maria Immacolata Vassallo. Telenovela Brasileira: uma narrativa sobre a nação. In: Revista Comunicação \& Educação. n. 26, p. 17-34, jan./abr. 2003.

MALCHER, Maria Ataide. Teledramaturgia: agente estratégico na construção da TV aberta brasileira. São Paulo: INTERCOM, 2009.

MARTÍN-BARBERO, Jesús. Dos meios às mediações: comunicação, cultura e hegemonia. $4^{\mathrm{a}}$ edição. Rio de Janeiro: Editora UFRJ, 2006.

Ofício de cartógrafo: travessias latino-americanas da comunicação na cultura. São Paulo: Edições Loyola, 2004.

MILANEZ, N. Discurso e imagem em movimento: o corpo horrorífico do vampiro no trailer. São Carlos: claraluz, 2011.

MIGNOLO, Walter. Histórias Locais / Projetos Globais: Colonialidade, Saberes Subalternos e Pensamento Liminar. Belo Horizonte: Editora UFMG, 2003.

MOTTER, Maria Lourdes. Ficção e realidade: a construção do cotidiano na telenovela. São Paulo: Editora Alexa Cultural, Comunicação \& Cultura, 2003.

MONARCHA, H. Redes Sociais e Sociedades Indígenas: entre dígitos e jenipapo. Dissertação de Mestrado. Belém: Universidade da Amazônia, 2012.

NEVES, I. A invenção do índio e as narrativas orais Tupi. Tese (doutorado) Universidade Estadual de Campinas, Instituto de Estudos da Linguagem. Campinas, SP: [s.n.], 2009.

ORTIZ, Renato. A Modernidade Tradição Brasileira. São Paulo: BRASILIENSE, 1988.

SARLO, Beatriz. Cenas da vida pós-moderna. Intelectuais, arte e vídeo-cultura na Argentina. Rio de Janeiro: UFRJ, 1997.

SOUZA SANTOS, B. Pela mão de Alice. São Paulo: Cortez, 2010. 
TOCANTINS, Raimundo. Mulheres indígenas no facebook: corpos, intericonicidade e identidades. Dissertação de Mestrado. Belém: Universidade da Amazônia, 2013.

ZUMTHOR, Paul. A letra e a voz.São Paulo: Companhia das Letras, 1993

WOLTON, Dominique. Internet, e depois? Uma teoria crítica das novas mídias. Porto Alegre: Sulina - 2a Edição, 2007. 